\title{
Buyer Perceptions of Supply Disruption Risk: A Behavioral View and Empirical Assessment
}

\author{
Scott C. Ellis \\ Clemson University, ellis9@clemson.edu \\ Raymond M. Henry \\ Cleveland State University, r.henry22@csuohio.edu \\ Jeff Shockley \\ Radford University, tjshockley@radford.edu
}

Follow this and additional works at: https://engagedscholarship.csuohio.edu/bus_facpub

Part of the Management Information Systems Commons

How does access to this work benefit you? Let us know!

\section{Publisher's Statement}

NOTICE: this is the author's version of a work that was accepted for publication in Journal of Operations Management. Changes resulting from the publishing process, such as peer review, editing, corrections, structural formatting, and other quality control mechanisms may not be reflected in this document. Changes may have been made to this work since it was submitted for publication. A definitive version was subsequently published in Journal of Operations Management, 28 (2010); 10.1016/j.jom.2009.07.002

\section{Original Published Citation}

Ellis, S. C., Henry, R. M., Shockley, J. (2010). Buyer Perceptions of Supply Disruption Risk: A Behavioral View and Empirical Assessment. Journal of Operations Management, 28, pp. 34-46.

This Article is brought to you for free and open access by the Monte Ahuja College of Business at EngagedScholarship@CSU. It has been accepted for inclusion in Business Faculty Publications by an authorized administrator of EngagedScholarship@CSU. For more information, please contact library.es@csuohio.edu. 


\title{
Buyer perceptions of supply disruption risk: A behavioral view and empirical assessment
}

\author{
Scott C. Ellis ${ }^{\text {a,* }}$, Raymond M. Henry ${ }^{\text {b }}$, Jeff Shockley ${ }^{c}$ \\ a Clemson University, Department of Management, 123D Sirrine Hall, Clemson, SC 29634-1305, United States \\ ${ }^{b}$ Clemson University, Department of Management, 107 Sirrine Hall, Clemson, SC 29634-1305, United States \\ ${ }^{\mathrm{c}}$ Radford University, Department of Management 130 Whitt Hall, Radford, VA 24142, United States
}

\section{Introduction}

One of the primary goals of supply management is to secure uninterrupted flows of direct materials from the supply base (Kraljic, 1983). This goal is becoming more difficult to achieve as firms source important direct materials within supply chains of increasing complexity. This sourcing trend increases buying firms' exposure to risks stemming from supply disruption. The need to ensure continuity of supply has motivated several related streams of research that quantify the negative implications of supply disruptions (Hendricks and Singhal, 2005a,b), propose frameworks for analyzing and reducing supply disruption risk (Kleindorfer and Saad, 2005), and identify environmental and organizational factors that drive supply disruptions (Sheffi and Rice, 2005). While these research streams lend significant insights into the causes, effects,

\footnotetext{
- Corresponding author. Tel.: +1 864656 6321: fax: +1 8646562015 . E-mail addresses: ellis9@clemson.edu (S.C. Ellis), rhenry@clemson.edu (R.M. Henry), tjshockley@radford.edu (J. Shockley).
}

and management of supply disruption risk, little research has sought to understand how views of supply disruption risk are developed and how these views affect the decision-making process.

This paper addresses this gap in extant literature by incorporating behavioral risk theory into the study of supply disruption risk. Building on the initial developments of Zsidisin (2003), we adapt Yates and Stone's (1992b) model of risky decision-making as the conceptual framework for our study. In accordance with their model, we investigate the causal relationships amongst situation, representations of risk, and decision-making within the purchasing domain. To gain further understanding of the decision-making process, we examine the role of three representations of supply disruption risk: magnitude of supply disruption, probability of supply disruption, and overall supply disruption risk. Using survey data from buyers, we examine how the supply environment influences representations (i.e., buyers' perceptions) of risk, which in turn affect buyers' decisions to search for alternate suppliers. We draw from transaction cost economic (TCE) theory (Williamson, 1985) and resource dependence theory (RDT) (Pfeffer and Salancik, 
1978) to identify four salient attributes of the supply environment that affect representations of supply disruption risk: technological uncertainty, market thinness, item customization, and item importance. Previous supply management research suggests that these factors are particularly germane to the decision-making context of our study (Kraljic, 1983).

Our research contributes to the body of supply chain management literature in two important ways. First, this study lends insights into how buyers' perceptions of supply disruption risk are formed. Through our analysis, we validate that buyers' perceptions of magnitude of disruption, probability of disruption, and overall supply disruption risk facilitate the translation of situation to decision. While previous conceptualizations of the risky decisionmaking process offer alternate views (Yates and Stone, 1992b), our findings show that the omission of any of these representations of supply disruption risk leads to an incomplete and inaccurate view of the decision-making process. Second, we operationalize and validate perceptual measures of supply disruption risk using a multi-step approach to scale development and validation. We do not investigate disruption events per se; rather, we develop perceptual measures to better understand how buyers and purchasing managers internalize and process supply disruption risk. Understanding perceptions of risk is essential because appraisals of risk are subjective and actions regarding risks are based on perceptions (Yates and Stone, 1992b). Therefore, the perceptual measures of supply risk developed within this paper may serve as the basis for future research that simultaneously examines the environmental factors that drive supply risk, the behavioral factors that affect managers' perceptions of supply risk, and the multiple tactics that may be used to mitigate supply risk.

The remainder of this paper is organized as follows. In Section 2, we review the conceptual underpinnings of behavioral risk that inform our theoretical model. In Section 3, we develop our research model and hypotheses. Our hypotheses examine the relationships amongst representations of supply disruption risk, the situational factors that drive these representations, and buyers' decisions to search for alternate suppliers. In Sections 4 and 5, we discuss our methodology, statistical analyses, and findings. In Section 6, we highlight the academic and managerial implications of our study. We conclude by noting the limitations of our study and offering recommendations that may guide future studies of supply disruption risk.

\section{Literature review}

We define supply disruptions as unforeseen events that interfere with "the normal flow of goods and[/or] materials within a supply chain" (Craighead et al., 2007, p. 132). Supply disruptions can be characterized as glitches (Hendricks and Singhal, 2003) and may be attributable to many factors including supply market complexities and the importance of the purchased product (Kraljic, 1983). Supply disruptions may have immediate or delayed negative effects on buying firm performance over the short and/ or long-term, pending the severity of the disruption and the buying firm's recovery capabilities (Sheffi and Rice, 2005). Whereas revenue loss from disruptions may stem from the inability to meet demand and inventory mark-downs, "expediting, premium freight, obsolete inventory, additional transactions, overtime, storage and moving, selling, and penalties paid to customer" drive operating costs higher (Hendricks and Singhal, 2003, pp. 503-504). Supply disruptions can also hamper productivity and capacity utilization for the buying firm, and may negatively affect a buying firm's ability to satisfy its customers. Empirical studies have found that supply disruptions negatively affect shareholder value and firms' operating and long-term stock price performance (Hendricks and Singhal, 2003, 2005a,b). Consequently, extant research has focused on the role of several supply management strategies, such as searching for and developing alternate sources of supply, to mitigate the risks associated with supply disruption (Kraljic, 1983).

Zsidisin (2003) incorporates the notion of supply disruption within his conceptualization of supply risk and suggests that behavioral theory may be leveraged to deepen understanding of the risk construct. Within the behavioral literature, risk has been studied in terms of "the amount at stake" (Cox and Rich, 1964, p. 33), loss potential (Yates and Stone, 1992b), and hazards (Slovic, 1987). Importantly, subjective judgments of risk are a significant determinant of managerial and consumer choice. Perceptions of risk influence adoption of business and supply strategy (Kraljic, 1983; Mintzberg, 1978), expected rates of return (McNamara and Bromiley, 1999), purchasing and executive decision-making (March and Shapira, 1987; Qualls and Puto, 1989), consumer purchase decisions (Kaplan et al., 1974), and consumer information search strategy (Dowling and Staelin, 1994).

Managers do not view risk as prescribed by classical decision theory; instead, behavioral research suggests that perceptual rather than objective assessments of risk guide decision-making behavior (March and Shapira, 1987). Similarly, Mitchell (1999, p. 164 ) asserts that "it is not objective risk which motivates behavior, but the consumer's impressions of it". Even when objective data is available to support decision-making, issues related to interpretation may interject bias into the risk assessment process (Yates et al., 1994). Therefore, we adopt the view that perceptions of risk, rather than objective measures, are the fundamental drivers of behavior.

The notion of loss is inherent in the concept of risk and outcome references play a formative role in individual's assessments of loss (Yates and Stone, 1992a). Sullivan and Kida (1995) note that individuals evaluate alternatives relative to an outcome reference to estimate gains and losses. Outcomes preferable to a reference outcome are gains; those less desirable than the reference outcome are losses (Yates and Stone, 1992a; Lopes, 1987). While there are several types of reference outcomes, target reference outcomes are particularly germane to our study of supply disruption risk. Yates and Stone (1992a, p. 8) describe a target reference outcome as "an outcome a person actively works to obtain" and acknowledge that target reference levels may be set by "individuals for themselves" or by "other people". Results from previous empirical studies of managerial behavior indicate that managers perceive risk relative to target reference outcomes set by an organization (Scott and Petty, 1984). For example, Mao (1970, p. 353) found that executives defined risk as "the prospect of not meeting the target rate of return." Similarly, Qualls and Puto (1989) find that organizational factors, rather than risk attitudes, affect industrial buyers' risk assessments.

Multiple factors are often used to measure and evaluate risk. Studies of consumer behavior suggest that overall perceived risk for a particular consumer product is a function of financial, social, psychological, physical, and performance risks (Kaplan et al., 1974). Interestingly, several measures of risk (e.g., financial and performance risk) were operationalized in terms of loss within these studies. Other researchers view perceived risk in terms of probability and magnitude of loss. Whereas the probability of loss refers to the likelihood that a particular loss may be realized, magnitude of loss captures the significance of a particular outcome (Yates and Stone, 1992a). Dash et al. (1976) adopt this view and measure perceived risk in terms of uncertainty of product satisfaction and consequence of unsatisfactory product performance. Similarly, Slovic (1987) characterizes the risks of 30 activities and technologies in terms dread risk (magnitude of loss) and unknown risk (probability of loss). In a review of the consumer perceived risk literature, Mitchell (1999) highlights numerous studies that conceptualize risk in terms magnitude and probability. 


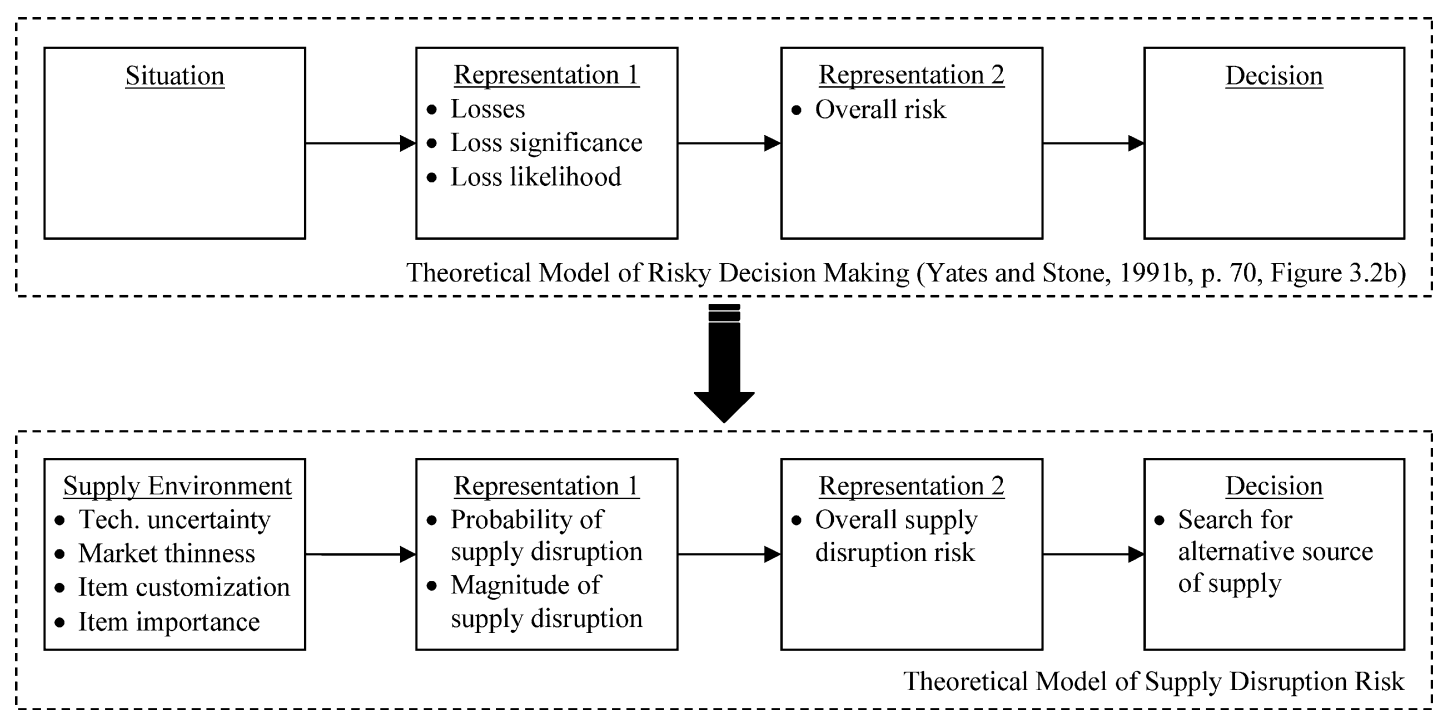

Fig. 1. Theoretical model.

Yates and Stone (1992b) incorporate magnitude and probability of loss within a four-stage behavioral model of risky decisionmaking. As shown in the top of Fig. 1, Yates and Stone posit that (1) situation, (2) representations of probability of loss and magnitude of loss, (3) overall risk assessment, and (4) decision form the essential stages of the decision-making process. In this model, loss significance, loss likelihood, and overall risk are positioned as related, but distinct representations of risk. In contrast with the traditional risk management literature, Yates and Stone distinguish between two successive stages of risk decision-making: judgment and evaluation. They argue that individuals first judge the probability of loss, magnitude of loss, and other relevant considerations before evaluating overall risk. Accordingly, individuals effectively synthesize their judgments of loss with judgments of other considerations to form an evaluation of overall risk. It is this appraisal of overall risk, not the probability or magnitude of loss that directly influences decision-making.

\section{Theoretical model of supply disruption risk}

We adapt Yates and Stone's (1992b) model of risky decisionmaking to the study of supply disruption risk. To facilitate our study, we adopt the purchase of a particular direct material from a specific supplier as the context and the buyer-supplier transaction as the unit of analysis of our study. The focal decision for our study is a buyer's decision to search for an alternate source of supply. As shown in the bottom of Fig. 1, we posit that representations of magnitude and probability of disruption are the primary determinants of overall supply disruption risk. Further, we assert that buyers' perceptions of overall supply disruption risk directly influence their decision to search for new sources of supply.

Situation is the salient factor that affects representations of risk. We draw on the work of Baird and Thomas (1985) and examine situation in terms of environmental factors. TCE and RDT suggest four salient supply environment factors that may affect representations of supply disruption risk for a given purchased material: technological uncertainty, market thinness, item customization, and item importance. We acknowledge that these supply environment attributes do not represent a comprehensive list of all the factors affecting representations of supply disruption risk; rather, our purpose is to illustrate how representations of supply disruption risk facilitate the translation of these salient situational factors into buyers' decisions. The following sections develop the theoretical support for each of the hypothesized relationships in our model.

\subsection{Overall supply disruption risk}

We define overall supply disruption risk as an individual's perception of the total potential loss associated with the disruption of supply of a particular purchased item from a particular supplier. Risk cannot exist in the absence of potential loss (Yates and Stone, 1992b); this central tenet is consistent with early conceptual and empirical studies of consumer behavior (Kaplan et al., 1974) and subsequent studies of perceived risk (March and Shapira, 1987; Slovic, 1987). Further, our definition is based on a perceptual rather than objective view of risk; prior research suggests that actual behavior often deviates from that predicted by expected utility theory (Fischhoff, 1992; Kahneman and Tversky, 1979). We limit the context of our supply disruption risk definition to a particular product purchased from a particular supplier. Several studies of industrial buyer behavior (Hahn et al., 1986; Treleven and Schweikhart, 1988) indicate that both the specific purchased product and particular supplier influence perceptions of risk. Finally, we note that our definition does not incorporate specific forms of loss, like financial, psychological, performance, physical, or social loss (Kaplan et al., 1974) or causes of loss, such as losses due to strikes, fires, natural disasters, or poor performance (Treleven and Schweikhart, 1988). Loss occurs when the target reference (i.e., expectation that supply occurs without failure) is not met; thus, our definition of overall supply disruption risk subsumes the different forms of loss attributable to unforeseen events that interfere with the normal flow of materials and/or goods (Craighead et al., 2007).

Our overall supply disruption risk definition differs substantively from classical definitions of perceived risk, which directly incorporate the probability and magnitude of loss. Conceptually, perceived risk has been defined in terms of chance and danger (Kogan and Wallach, 1964), the amount lost and feelings of certainty (Cunningham, 1967), and the potential occurrence of events having detrimental effect (Zsidisin and Smith, 2005). Perceived risk has also been measured as a multiplicative combination of probability and magnitude of loss (Cunningham, 1967; Peter and Ryan, 1976). However, this approach may be misguided. In particular, Kaplan and Garrick (1981) note the difficulty in equating the risk of a high probability-low magnitude 
loss scenario with one characterized by low probability and high magnitude of loss. Further, March and Shapira (1987) find that magnitude of loss influences risk perception to a much greater extent than probability of loss; in extreme cases, executives completely discounted the notion of loss probability. In such cases, a multiplicative model of perceived risk does not capture the perceived risk attributable to magnitude of loss.

While many definitions of risk incorporate both probability and magnitude of loss, Yates and Stone (1992b) suggest that probability and magnitude of loss play a formative role in the development of risk perceptions. A key difference between these successive stages of assessment is the distinction between judgments and decisions (Yates, 1990). A judgment is "an opinion about what is or will be the state of some aspect of the world", whereas an overall risk appraisal is "a type of decision, specifically a partial evaluation" (Yates and Stone, 1992b, p. 68). As a type of decision, overall risk appraisals play an important role in determining behavior. Shapira (1995) supports this notion by suggesting that executives base decisions on a "feel" of overall risk. Similarly, Yates and Stone (1992b) indicate that managers describe projects in terms of "overall riskiness". Consistent with Yates and Stone's prescriptions (1992b), we argue that overall supply disruption risk assessments are driven by buyers' judgments of the magnitude and probability of supply disruption they are facing. We define probability of supply disruption as the perceived likelihood that a supply disruption will occur and the magnitude of supply disruption as the perception of the severity of losses that may result from a disruption.

H1a. Probability of supply disruption is positively associated with overall supply disruption risk.

H1b. Magnitude of supply disruption is positively associated with overall supply disruption risk.

\subsection{Antecedents of supply disruption risk}

We draw from TCE and RDT to identify product and supply market factors that we hypothesize will affect perceptions of supply disruption magnitude, supply disruption probability, or both. Both TCE and RDT describe exchange relationships between organizations and have been employed extensively in the study of buyersupplier relationships. While the two theories are often contrasted against each other, there is significant overlap in their predictions (Ulrich and Barney, 1984). Both TCE and RDT explain how organizations choose governance structures in the face of uncertainty; so factors identified from these theories are of particular interest in understanding perceptions of supply disruption risk.

TCE focuses on the costs associated with exchange governance by identifying governance mechanisms (markets or hierarchies) that are most appropriate for a given set of exchange conditions (Williamson, 1991). The selection of an appropriate governance structure is driven by asset specificity and the degree of uncertainty. Actors will favor markets when transactions are characterized by a limited need for adaptation, coordination, and safeguarding. RDT argues that organizations are dependent on their environmental contexts to obtain resources (Pfeffer and Salancik, 1978). Differences in dependencies allow organizations to exert power and influence over other organizations. Because increased dependence increases exposure to risk, organizations try to limit dependence on other organizations whenever possible (Smeltzer and Siferd, 1998). Two factors are important in determining dependence: (1) the importance of the resource and (2) the concentration of resource control.

From these two theoretical perspectives, we identify important supply market and product characteristics that impact perceptions of the probability and magnitude of supply disruption. Specifically we examine technological uncertainty, market thinness, item customization, and item importance.

\subsubsection{Technological uncertainty}

Technological uncertainty represents the rate of change in underlying technologies of a purchased product (Stump et al., 2002). Technological uncertainty makes it more difficult to forecast future developments as unforeseen events unfold and new opportunities and threats arise (Bensaou and Anderson, 1999; Cannon and Perreault, 1999). Technological uncertainty also increases the difficulty of processing supply market information. Standards for product price and quality performance may be difficult to establish in uncertain environments, making it difficult to apply safeguarding tactics (Stump and Heide, 1996). By causing changes in the market and reducing buyers' ability to adjust to these changes, technological uncertainty increases the likelihood of a supply disruption.

H2. The level of technological uncertainty is positively associated with the probability of supply disruption.

The firm's desire to maintain levels of innovation is one of the key drivers of technological uncertainty (Auster, 1992). However, the pursuit of innovation imposes limitations on product development capacity because of the lack of perfect information (Petersen et al., 2003). Turbulence associated with high technological uncertainty requires increased interaction between buyer and supplier (Lazzarini et al., 2008). Firms often seek to reduce uncertainty by establishing tighter relationships with suppliers (Dyer and Singh, 1998). This requires organizations to make relationship specific investments (Stuart et al., 1998). Because of these investments, disruptions in supply cannot be easily managed by turning to another supplier; thus, the difficulty of switching suppliers increases the impact of those disruptions.

H3. The level of technological uncertainty is positively associated with the magnitude of supply disruption.

\subsubsection{Market thinness}

Market thinness is the "the degree to which a buying firm has [a limited number of] alternative sources of supply to meet a need" (Cannon and Perreault, 1999, p. 444). Thin markets reduce buyer alternatives because there are fewer suppliers. Consequently, direct materials sourcing in thin supply markets is subject to opportunistic supplier behavior (Bensaou and Anderson, 1999; Grover and Malhotra, 2003). Furthermore, there is reduced information because, in thin markets, few suppliers sell comparable goods (Cannon and Perreault, 1999, p. 444). This suggests two important mechanisms that support a positive relationship between market thinness and likelihood of supply disruption: (1) lock-in and (2) reduced information flow.

H4. The level of supply market thinness is positively associated with the probability of supply disruption.

When there are fewer available suppliers, sourcing organizations will be more dependent on those firms (Pfeffer and Salancik, 1978). In thin markets, suppliers have greater power because the resources they supply cannot be obtained from other sources. Having fewer alternatives increases the negative impact from a supply disruption because sourcing organizations are not in a position to easily switch suppliers (Gassenheimer and Monolis, 2001; Yeh, 2005). This inability to acquire needed resources from alternate suppliers means that sourcing organizations will bear the full brunt of the costs associated with the disruption.

H5. The level of supply market thinness is positively associated with the magnitude of supply disruption. 


\subsubsection{Item customization}

We define item customization as the extent to which purchased items are modified according to the specifications of a specific buyer (Hegde et al., 2005; Perdue and Summers, 1991). Customer-specific product adaptations necessitate specialized investments in plants, manufacturing equipment and processes, and/or worker skills (Hallen et al., 1991). By developing transaction-specific assets, suppliers achieve efficiencies in the provision of goods that more closely match buyers' requirements (Stump et al., 2002). Importantly, these transaction-specific investments also raise buyers' switching costs (Hallen et al., 1991; Stump et al., 2002). Increased switching costs associated with the purchase of customized items reduce buyers' abilities to deter suppliers' opportunistic behavior and the production of non-standardized products introduces new processes which may be problematic (Hegde et al., 2005). Both of these increase the likelihood of supply disruption.

H6. The level of item customization is positively associated with the probability of supply disruption.

Buyer specific adaptations to form, features, and/or fit enable customized components to enhance the internal or external quality of the buyer's final product (Clark and Fujimoto, 1990). Relative to standardized, off-the-shelf components, customized inputs minimize the need for functional compromise. Therefore, the supply of customized items may significantly affect the success of a buying firm's low cost or differentiation strategy. Consequently, when outsourcing involves customized items, a supplier's failure to deliver will have significant negative consequences for the buying firm.

H7. The level of purchased item customization is positively associated with the magnitude of supply disruption.

\subsubsection{Item importance}

Item importance represents the degree to which a purchased part is critical to the manufacture of an organization's other parts, components, or end-products (Cannon and Perreault, 1999; Krause, 1999). An item may be important either because it represents a large proportion of the required inputs or is a particularly important element in a firm's end-product(s) (Kraljic, 1983). Several studies have found that the buying firm's perception of the financial and strategic significance of a particular purchased item has a significant effect on supply chain activities and behaviors (Cannon and Perreault, 1999; Krause, 1999). The fact that a component is important increases an organization's vulnerability if acquisition of the resource is no longer assured. From the riskbased perspective, a buying firm experiences more significant losses from a supply disruption for critical items.

H8. The level of purchased item importance is positively associated with the magnitude of supply disruption.

\subsubsection{Search for alternative source of supply}

The search for suppliers is one of the key activities in the organizational buying process (Johnston and Lewin, 1996). While contemporary sourcing approaches emphasize repeated purchases with an incumbent supplier (Kim et al., 2008), organizations must also mitigate the risks associated with the supply of purchased goods. High supplier performance will encourage the continuation of a relationship with a supplier (Kim et al., 2008; Anderson and Weitz, 1989). Conversely, as buyers perceive greater overall risk in the supply of a particular item from a specific supplier they will seek to reduce the risk by searching for alternative sources of supply. The decision to search for alternatives will be based on an assessment of overall supply disruption risk given the situation associated with the incumbent supplier.
H9. Overall supply disruption risk is positively associated with the search for alternative sources.

\subsubsection{Exogenous correlations}

While the product and market constructs included in the model are distinct, the underlying causal mechanisms at work for some of these factors overlap. This is particularly true for item customization. When purchase items are customized for a particular buyer, this serves to both restrict the choices of the buying firm and increase the importance of the customized item. Choice is limited because of specific investments made by the supplying organization in producing the customized item. This serves to create an artificially thin market because buyers cannot readily find another supplier with the same capability (Cannon and Perreault, 1999; Stump et al., 2002). Customized items take on an increased importance because of both their functional attributes (Ulrich and Ellison, 1999) and their value to the final product (Clark and Fujimoto, 1990). Accordingly, we include exogenous correlations in our model between item customization-market thinness and item customization-item importance to account for the shared mechanisms affecting perceptions of supply disruption probability and magnitude.

\section{Methodology}

\subsection{Research instrument development}

We used a multi-step process to initially develop and subsequently validate our instrument (Churchill, 1979). Initially, we conducted an extensive review of the operations, marketing, and supply chain management literature to identify relevant constructs, operational definitions, and survey measurement items. Whenever possible, validated measures from previous research were incorporated into this study. We adapted existing questions to measure market thinness (five-item scale developed by Cannon and Perreault, 1999), technological uncertainty (threeitem scale developed by Stump et al., 2002), and product customization (four-item scale developed by Stump et al., 2002). Further, we developed a six-item scale for item importance that: (1) incorporates the notions of importance, essentiality, priority, and significance from Cannon and Perreault's (1999) four-item bipolar scale for supply importance; and (2) draws from Krause's (1999) operationalization of "importance of purchased inputs" as it relates to top management attention. Finally, we adapted a single item from Kim et al. (2008) to measure search for alternate source of supply.

Prior literature provides little guidance for operationalizing the magnitude of supply disruption, probability of supply disruption, and overall supply disruption risk constructs. Consequently, we drew from the behavioral risk literature to develop initial items that were consistent with our operational definitions. Specifically, we incorporated the conceptual works of Yates and Stone (1992a, 1992b) and Zsidisin (2003) into the initial development of item measures for the probability and magnitude of supply disruption constructs. Our measure of overall supply disruption risk is based upon Yates and Stone's (1992b), Shapira's (1995), and Slovic's (1987) conceptual development of overall risk. Consistent with Shapira's (1995) findings, we developed a single-item measure that captures buyers' overall "feel" of supply disruption risk.

In the subsequent stages of scale development, we conducted interviews and pre-tests with low-, mid-, and executive-level managers representing both buyers and suppliers from the automotive components, specialized fastener, plastic resin, and part/package labeling industries. Our findings yielded several insights that affected the methodology of our study. First, the 
completion time for the entire questionnaire ranged from 24 to $43 \mathrm{~min}$; consequently, many measurement items were eliminated from the questionnaire. Second, when given the choice, respondents tended to select their most important supplier relationship to serve as the basis for the questionnaire. As such, we modified our sampling methodology to ensure collection of survey response data that included supplier relationships of both major and minor importance. Third, our interviews indicated a potential disconnect between the desired behaviors sought by purchasing executives and the actual behaviors exhibited by purchasing managers and buyers. Therefore, we specifically targeted buyers and purchasing managers, rather than executives, to form the basis of our sample frame.

Next, we conducted a pilot study in which we administered print and web-based questionnaires to a cross-section of purchasing professionals affiliated with six chapters of the Institute for Supply Management (ISM) located in the Northeast United States. We assessed the response data using exploratory factor and reliability analyses. Our assessment suggested that several items loaded poorly onto their intended constructs; as indicated in Tables $2 \mathrm{a}$ and $2 \mathrm{~b}$, these measurement items were dropped from this study. The resulting multi-item constructs exhibited acceptable psychometric properties: (1) no substantive cross-loadings were evidenced, (2) all Cronbach's alpha values were greater than $0.7,(3)$ all composite reliability values were greater than 0.7 , and (4) all average variance extracted values were greater than 0.5 .

\subsection{Sample frame and data collection}

The sample frame of our primary study consisted of 3196 Title 2 and Title 3 purchasing professionals randomly selected from a list of ISM members. Generally, Title 2 and Title 3 ISM members are mid-level purchasing professionals with titles such as buyer, senior buyer, and purchasing/supply chain manager. This sample frame facilitated the study of the perceptions of buyers who manage supplier relationships on a day-to-day basis. Additionally, a stratified sample was randomly drawn across U.S. manufacturing industries having two-digit SIC's between 20 and 39, thereby targeting a cross-section of purchasing professionals that manage the procurement of direct materials across a wide range of U.S. manufacturing industries.

Data collection was completed in January 2007. In total, 223 direct material buyers and purchasing managers returned their completed questionnaires; this resulted in an effective response rate of $7.1 \%$ for our study. The relatively low response rate may be attributable to two key factors. First, our contact list excluded telephone and email contact information and, to a large extent, employer information. Prior to survey administration, it was not possible to verify that each member of our sample frame was an active purchasing professional employed by a manufacturing firm. Second, it was not possible, a priori, to identify potential respondents who actively purchased direct materials. Consequently, we sent questionnaires to buyers of both direct and indirect materials. We received 69 notifications via phone, email, or returned surveys from those that said they were retired, with a different company, in a new position, or otherwise not currently involved in the purchase of direct materials.

\subsection{Survey instructions}

Prior to survey administration, potential respondents were randomly separated into two groups. Pending group membership, respondents were asked to identify a direct material supplier of either major or minor importance that they "actively manage on a
Table 1a

Annual sales of buying firms.

\begin{tabular}{lc}
\hline Total annual sales $(\$)$ & Frequency \\
\hline$<50$ million & 46 \\
$50-299.9$ million & 44 \\
300 million-999.9 million & 28 \\
$1-4.9$ billion & 30 \\
$\geq 5$ billion & 29 \\
Missing & 46 \\
Total & 223
\end{tabular}

Table 1b

Purchases from Supplier Y.

\begin{tabular}{lll}
\hline Total annual sales (\$) & $\begin{array}{l}\text { Annual purchases of } \\
\text { Item X from Supplier } \\
\text { Y (frequency) }\end{array}$ & $\begin{array}{l}\text { Total annual purchases } \\
\text { from Supplier Y } \\
\text { (frequency) }\end{array}$ \\
\hline$<100$ thousand & 21 & 13 \\
100-499.9 thousand & 44 & 21 \\
$500-999.9$ thousand & 15 & 23 \\
1-2.9 million & 40 & 39 \\
3-9.9 million & 24 & 43 \\
$10-49.9$ million & 24 & 27 \\
$\geq 50$ million & 16 & 17 \\
Missing & 39 & 40 \\
Total & 223 & 223 \\
\hline
\end{tabular}

regular basis". ${ }^{1}$ Throughout the questionnaire, this supplier was referred to as "Supplier Y". Respondents were also instructed to identify a direct material purchased from this supplier and an endproduct into which the purchased item was incorporated. The direct material and end-product selections were referred to as "Item X" and "Product Z", respectively, throughout the questionnaire. Using this approach, the questionnaire was customized to each respondent's specific purchasing situation. We used 20 items to test our behavioral model of supply disruption risk. The final list of measurement items and associated constructs is presented in Tables $2 \mathrm{a}$ and $2 \mathrm{~b}$.

\subsection{Overview of statistical methods}

We applied structural equation modeling techniques to validate our measures and test our hypotheses. For cross-validation purposes, the measurement and structural models were independently estimated using AMOS (v6) and EQS (v6). In all cases, results were consistent across software platforms; hence, we report only those estimated by AMOS.

\section{Analysis and findings}

\subsection{Respondent profile and survey biases}

The demographic profile of the respondents for this study is provided within Tables 1a-1d. Most respondents identified themselves as Purchasing Managers. Approximately 73\% of the respondents were men and roughly $45 \%$ of respondents held at least one professional certification from ISM (i.e., C.P.M. or A.P.P.). Over $85 \%$ had more than eight years experience managing the supply of purchased materials, with none having fewer than three years of purchasing experience. 52.5\% of the respondents answered their questionnaire with respect to a supplier of major importance; $40.4 \%$ of the responses are based on supplier

\footnotetext{
${ }^{1}$ This approach prevented potential losses in response variance and generalizability that may have occurred if all participants chose their most important supply relationship as the context for their survey response.
} 
Table 1c

Supplier relationships of major versus minor importance.

\begin{tabular}{|c|c|c|c|c|c|c|}
\hline $\begin{array}{l}\text { Relationship } \\
\text { importance }\end{array}$ & $\begin{array}{l}\text { Contract } \\
\text { (frequency) }\end{array}$ & $\begin{array}{l}\text { Spot buy } \\
\text { (frequency) }\end{array}$ & $\begin{array}{l}\text { Buy type missing } \\
\text { (frequency) }\end{array}$ & $\begin{array}{l}\text { Total } \\
\text { (frequency) }\end{array}$ & $\begin{array}{l}\text { Average contract } \\
\text { length (months) }\end{array}$ & $\begin{array}{l}\text { Average relationship } \\
\text { length (years) }\end{array}$ \\
\hline Major & 93 & 21 & 3 & 117 & 19.18 & 11.81 \\
\hline Minor & 69 & 20 & 1 & 90 & 19.35 & 9.78 \\
\hline Missing & 13 & 2 & 1 & 16 & 23.82 & 12.93 \\
\hline Total & 175 & 43 & 5 & 223 & 19.54 & 11.04 \\
\hline
\end{tabular}

Table 1d

Direct material purchases.

\begin{tabular}{lc}
\hline Direct material type & Frequency \\
\hline Raw material & 88 \\
Component & 88 \\
Assembly & 34 \\
System & 8 \\
Missing & 5 \\
Total & 223 \\
\hline
\end{tabular}

relationships of minor importance. The average length of relationship between respondents' companies and their suppliers is 11.04 years and respondents managed a median of $\$ 1 \mathrm{M}-2.9 \mathrm{M}$ in annual purchases of "Item X" from "Supplier Y". 78.5\% of the supply relationships reported in this study are contractual; $18.4 \%$ of the responses are based on spot buys. For those reporting contractual buys, the average length of contract is 19.5 months. The majority of the respondents (78.9\%) answered the questionnaire with respect to a raw material or component purchase.

Non-response bias was assessed by comparing industry membership, geographic location, and annual sales revenue across (1) responders and non-responders and (2) early and late responders (Armstrong and Overton, 1977). ISM provided industry membership and address data for each member of our sample frame. We compared industry classification for both responders and nonresponders $\left(\chi^{2}=16.80, p=0.60\right)$ and early and late responders $\left(\chi^{2}=15.84, p=0.46\right)$ and found no significant differences. Using address data, we classified respondents into one of the eight Bureau of Economic Analysis geographic regions that comprise the continental U.S. Chi-squared tests were used to assess differences across geographical regions for both responders versus nonresponders $\left(\chi^{2}=3.78, p=0.81\right)$ and early versus late responders $\left(\chi^{2}=9.36, p=0.23\right)$; our results suggest no significant differences across geographic regions. To assess differences in firm sales across responders and non-responders, we randomly selected 100 nonresponders from our mailing list and recorded annual sales revenues for each of the non-responders' firms using secondary data from Hoovers and Reference USA databases. We contrasted this frequency distribution with the annual sales data reported by 177 survey participants. We found no significant difference in annual sales revenue across responders and non-responders $\left(\chi^{2}=7.46, p=0.11\right)$. Self-report data was used to assess differences in annual sales revenue across early and late responders; similarly, no significant differences were found $\left(\chi^{2}=1.26, p=0.87\right)$. In aggregate, these results suggest that, despite the low rate of response for this study, respondents adequately represent the population of ISM Title 2 and Title 3 buyers and purchasing managers who are employed within manufacturing industries.

An additional concern with single-respondent, questionnairebased measurement is the existence of common method variance (CMV). We assessed CMV using Harmon's one-factor test (Podsakoff and Organ, 1986). We conducted exploratory factor analysis with principal components extraction and no rotation for all variables in our model and found that six factors had Eigenvalues exceeding one with the first factor accounting for $26.24 \%$ of the variance. We also confirmed this finding in our confirmatory analysis (Byrne, 2006). While this does not rule out the presence of CMV, it is unlikely to be problematic.

\subsection{Results of the confirmatory factor analysis}

To assess the reliability and validity of the scales that were initially validated in the pilot study, we conducted confirmatory factor analysis (CFA) on our sample data $(n=223)$. Survey items, item descriptive statistics, factor loadings, $t$-values, and model fit statistics are listed in Tables $2 \mathrm{a}$ and $2 \mathrm{~b}$. Our results show acceptable model fit $\left(\chi^{2}=167.592, \quad\right.$ d.f. $=120, p=0.003$; RMSEA $=0.042 ; C F I=0.978 ;$ SRMR $=0.051)$ and that all item-tofactor loadings were significant $(p<0.01)$ and substantive $(\lambda>0.5)$. We examined items for loadings onto unintended factors and found no significant cross-loadings; these results provide evidence of scale unidimensionality.

We assessed the reliability of our scales using Cronbach's alpha, average variance extracted (AVE), and composite reliability (CR) scores. As reported in Table 3, all Cronbach's alpha and CR statistics exceed or are at the 0.7 cutoff established in the literature. In addition, all but one scale (probability of supply disruption) surpassed the accepted 0.50 cutoff for AVE. We re-assessed the AVE and $C R$ for the probability of supply disruption construct by conducting exploratory factor analysis on our pilot and follow-up ${ }^{2}$ datasets; our results indicate that the AVE exceeds 0.6 for both datasets ( 0.705 and 0.630 , respectively) and CR exceeds 0.8 for both datasets ( 0.877 and 0.836 , respectively). As such, we conclude that the convergent validity of our multi-item scales is adequate (Fornell and Larcker, 1981).

Two of our scales are based on single-item measures: overall supply disruption risk and search for alternate source of supply. We collected additional longitudinal data to validate our measure of overall supply disruption risk. In November 2008, we collected perceptual measures of supplier performance from 90 direct material buyers of a single manufacturing firm and culled objective supply disruption data from the same firm's archival database for the previous five-year period (measures shown in Table 4). Six months later, we asked the same respondents to rate overall supply disruption risk using our single-item measure. As presented in Table 5 , the results of our analysis show that overall supply disruption risk is significantly and negatively correlated with each perceptual measure of supplier performance. Additionally, we find that the total number of supply disruption cases and the total costs recovered from suppliers (due to disruptions) for the previous fiveyear period are significantly and positively related to overall supply disruption risk for all respondents and for those with five or more years of experience working with their matched supplier. Based on

\footnotetext{
2 To confirm the validity of our constructs, we administered our survey questionnaire to an additional random sample of Title 2 and Title 3 ISM purchasing professionals; we received 41 responses. Statistics derived from this "follow-up" sample provide additional support for the validity of the constructs used in this study.
} 
Table 2a

Survey items, item means, standard deviations, item loadings, and $t$-values from CFA for exogenous variables ${ }^{\mathrm{a}}$.

\begin{tabular}{|c|c|c|c|c|c|}
\hline \multicolumn{2}{|r|}{ Items ( 1 , strongly disagree; 4 , nuetral; 7 , strongly agree) } & Mean & S.D. & Loading $^{\mathrm{b}}$ & $t$-Value \\
\hline \multicolumn{6}{|c|}{ Item customization } \\
\hline IC1 & Item $\mathrm{X}$ is custom built for us & 2.26 & 1.44 & 0.861 & 15.053 \\
\hline IC 2 & We basically buy the same component that Supplier Y sells to other customers ${ }^{\mathrm{b}}$ & 3.51 & 1.72 & 0.734 & 12.182 \\
\hline IC 3 & Item $\mathrm{X}$ is pretty much an "off-the-shelf" item" ${ }^{\mathrm{c}}$ & 4.13 & 1.70 & 0.901 & 16.030 \\
\hline- & The specifications for Item X were substantially different from those of any other product that Supplier Y makes ${ }^{\mathrm{d}}$ & - & - & - & -- \\
\hline \multicolumn{6}{|c|}{ Technological uncertainty } \\
\hline TU1 & Rapid changes in Item X's industry necessitate frequent product modifications & 2.83 & 1.57 & 0.638 & 9.389 \\
\hline TU2 & Technology developments in Item X's industry are frequent & 3.21 & 1.64 & 0.788 & 11.717 \\
\hline TU3 & Technology changes in Item X's industry provide major opportunities & 3.33 & 1.58 & 0.756 & 11.233 \\
\hline \multicolumn{6}{|c|}{ Item importance } \\
\hline II1 & If our company ranked all purchased items in order of importance, Item X would be near the top of the list & 5.51 & 1.52 & 0.919 & 17.400 \\
\hline II2 & Compared to other items our company purchases, Item X is a high priority with our company's purchasing managers & 5.38 & 1.64 & 0.912 & 17.179 \\
\hline II3 & Most other items that our company purchases are more important than Item $\mathrm{X}^{\mathrm{c}}$ & 4.88 & 1.88 & 0.828 & 14.818 \\
\hline- & Item X represents one of our company's essential purchases ${ }^{d}$ & - & - & - & - \\
\hline- & Relative to other items that our company buys, Item $\mathrm{X}$ is of minor significance ${ }^{\mathrm{c}, \mathrm{d}}$ & - & - & - & - \\
\hline- & The purchase of Item X is critical to the success of our business ${ }^{\mathrm{d}}$ & - & - & - & - \\
\hline \multicolumn{6}{|c|}{ Market thinness } \\
\hline MT1 & We could purchase Item X from several other vendors ${ }^{c}$ & 2.93 & 1.80 & 0.686 & 10.577 \\
\hline MT2 & Supplier Y is really the only supplier we could use for Item X & 2.44 & 1.63 & 0.884 & 14.140 \\
\hline MT3 & Supplier Y almost has a monopoly for Item X & 2.10 & 1.48 & 0.716 & 11.097 \\
\hline- & The supply market for Item $\mathrm{X}$ is very competitive $\mathrm{e}^{\mathrm{c}, \mathrm{d}}$ & - & - & - & - \\
\hline- & No other vendor has Supplier Y's capabilities ${ }^{\mathrm{d}}$ & - & - & - & - \\
\hline
\end{tabular}

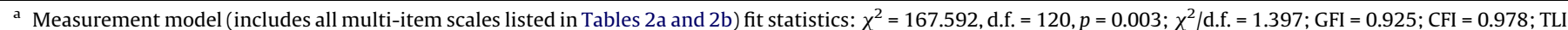
$(\mathrm{NNFI})=0.972 ; \mathrm{NFI}=0.928 ; \mathrm{RMSEA}=0.042 ; \mathrm{SRMR}=0.051$.

b Standardized coefficients; all loadings are significant at $p<0.001$.

c Reverse-coded item; item measure reversed by subtracting response value from 8 .

d Dropped after pilot study due to poor psychometric properties.

the results of our multi-method assessments, we conclude that our single-item measure of overall supply disruption risk is valid. We rely on the work of Kim et al. (2008) to demonstrate the validity of our single item measure of search for alternate source of supply. In their study of the Japanese electronics industry, Kim et al. (2008, p. 97) report that their item, "We are actively seeking an alternative supplier for this part", loads onto the search for alternative supplier construct at $\lambda=0.94$. Given this near perfect loading, we adapted this single-item measure for our study.

Using the measurement model as a baseline, we tested the discriminant validity of our latent constructs by conducting a series of pair-wise tests; in these tests, the covariance between each pair of latent constructs was constrained to one. Then, using global $\chi^{2}$ difference tests, we compared the fit of each constrained model to that of the baseline model (Bollen, 1989). Each constrained model resulted in a significant $\chi^{2}$ increase $(p<0.01)$ when compared the baseline model; the results of this analysis support the discriminant validity of our latent constructs. Also, we note that the inter-construct correlations and standard errors reported in Table 3 similarly support the discriminant validity of our constructs.

\subsection{Results of the structural model analysis}

Fig. 2 reports the estimation results for the structural model. The model fit statistics reported $\left(\chi^{2}=231.602\right.$, d.f. $=160, p=0.000$,

Table 2b

Survey items, item means, standard deviations, item loadings, and $t$-values from CFA for endogenous variables.

\begin{tabular}{|c|c|c|c|c|c|}
\hline \multicolumn{2}{|c|}{ Items (1, strongly disagree; 4, nuetral; $7 ;$ strongly agree) } & Mean & S.D. & Loading $^{\mathrm{a}}$ & $t$-Value \\
\hline \multicolumn{6}{|c|}{ Probability of supply disruption } \\
\hline PSD1 & It is highly unlikely that we will experience an interruption in the supply of Item $\mathrm{X}$ from Supplier $\mathrm{Y}^{\mathrm{c}}$ & 2.90 & 1.38 & 0.735 & 9.786 \\
\hline PSD2 & There is a high probability that Supplier Y will fail to supply Item $\mathrm{X}$ to us & 2.44 & 1.28 & 0.570 & 7.788 \\
\hline PSD3 & We worry that Supplier Y may not supply Item X as specified within our purchase agreement & 2.63 & 1.42 & 0.708 & 9.476 \\
\hline- & We are confident in Supplier Y's ability to supply Item X to us ${ }^{\mathrm{d}}$ & - & - & - & - \\
\hline \multicolumn{6}{|c|}{ Magnitude of supply disruption } \\
\hline MSD1 & $\begin{array}{l}\text { An interruption in the supply of Item X from Supplier Y would have severe negative financial } \\
\text { consequences for our business }\end{array}$ & 4.92 & 1.76 & 0.905 & 17.349 \\
\hline MSD2 & Supplier Y's inability to supply Item X would jeopardize our business performance & 4.81 & 1.80 & 0.959 & 19.173 \\
\hline MSD3 & We would incur significant costs and/or losses in revenue if Supplier Y failed to supply Item X & 4.78 & 1.78 & 0.927 & 18.073 \\
\hline- & Without the supply of Item X from Supplier Y, we would be unable to meet our customer's demand ${ }^{\mathrm{d}}$ & - & - & - & - \\
\hline- & Our relationships with our primary customers would be unaffected if Supplier Y failed to supply Item $X^{c, d}$ & - & - & - & - \\
\hline \multicolumn{6}{|c|}{ Overall supply disruption risk $k^{\mathrm{b}}$} \\
\hline OSR1 & Overall, the supply of Item $\mathrm{X}$ from Supplier $\mathrm{Y}$ is characterized by low levels of risk ${ }^{\mathrm{c}}$ & 2.26 & 1.58 & - & - \\
\hline \multicolumn{6}{|c|}{ Search for alternate source of supply } \\
\hline SAS1 & We are actively seeking alternate sources of Item X & 4.25 & 1.79 & - & - \\
\hline
\end{tabular}

a Standardized coefficients; all loadings are significant at $p<0.001$.

b Single item scale.

c Reverse-coded item; item measure reversed by subtracting response value from 8 .

d Dropped after pilot study due to poor psychometric properties. 
Table 3

Inter-construct correlations (standard errors), average variance extracted, and scale reliabilities.

\begin{tabular}{|c|c|c|c|c|c|c|c|c|c|c|}
\hline & Custom & TecUnc & ItmImp & MktThn & ProbSD & MagSD & OvrlRsk & Cron $\alpha$ & AVE & C.R. \\
\hline Custom & - & - & - & - & - & - & - & 0.869 & 0.697 & 0.869 \\
\hline TecUnc & $0.085(0.080)$ & - & - & - & - & - & - & 0.769 & 0.533 & 0.769 \\
\hline ItmImp & $0.178(0.072)$ & $0.267(0.074)$ & - & - & - & - & - & 0.911 & 0.787 & 0.911 \\
\hline MktThn & $0.218(0.074)$ & $0.155(0.081)$ & $0.198(0.073)$ & - & - & - & - & 0.796 & 0.588 & 0.796 \\
\hline ProbSD & $0.117(0.082)$ & $0.226(0.086)$ & $0.013(0.082)$ & $0.261(0.081)$ & - & - & - & 0.711 & 0.455 & 0.711 \\
\hline MagSD & $0.327(0.066)$ & $0.313(0.071)$ & $0.415(0.060)$ & $0.335(0.067)$ & $0.187(0.078)$ & - & - & 0.950 & 0.866 & 0.950 \\
\hline OvrlRsk & $0.252(0.067)$ & $0.224(0.072)$ & $0.157(0.068)$ & $0.258(0.068)$ & $0.468(0.065)$ & $0.270(0.064)$ & - & - & - & - \\
\hline AltSrc & $0.052(0.071)$ & $0.042(0.076)$ & $0.254(0.065)$ & $0.102(0.072)$ & $0.129(0.077)$ & $0.116(0.068)$ & $0.194(0.065)$ & - & - & - \\
\hline
\end{tabular}

Table 4

Measures of supplier performance and supply disruption.

\begin{tabular}{|c|c|}
\hline Scales & $\mathrm{d}$ associated indicators \\
\hline Suppli & erformance $e^{\mathrm{a}}$ \\
\hline $\begin{array}{l}\text { Please } \\
\text { expect }\end{array}$ & $\begin{array}{l}\text { dicate how Supplier Y's performance compares with your company's } \\
\text { ons for supplier performance for each of the following areas }\end{array}$ \\
\hline SP1 & Price \\
\hline SP2 & Conformance quality \\
\hline SP3 & Delivery reliability \\
\hline SP4 & Product technology \\
\hline SP5 & Cost reduction/avoidance \\
\hline SP6 & Total value \\
\hline Numbe & f supply disruptions \\
\hline NSD1 & $\begin{array}{l}\text { Log of the total number of supply disruption cases that occurred over } \\
\text { five-year period }\end{array}$ \\
\hline Numb & f supply disruptions \\
\hline CSD1 & $\begin{array}{l}\text { Log of the total cost of supply disruptions that occurred over five-year } \\
\text { period }\end{array}$ \\
\hline
\end{tabular}

a Response scale: 1, Falls Far Short; 4, Meets; 7, Far Exceeds.

RMSEA $=0.045, C F I=0.968$, SRMR $=0.081$ ) generally satisfy the guidelines for fit established in the structural modeling literature (Hu and Bentler, 1998, 1999). Overall, our model explains a substantive amount of the variance of overall supply disruption risk $\left(R^{2}=0.259\right)$, providing further evidence of the validity of our model of supply disruption risk.

The results of our statistical analyses provide support for eight of the nine hypothesized relationships in our proposed model. Our results indicate that both probability of supply disruption $\left(\beta_{23}\right.$ $=0.448, p<0.001)$ and magnitude of supply disruption $\left(\beta_{24}=0.189\right.$, $p<0.01$ ) have positive and statistically significant effects on overall supply disruption risk, providing support for $\mathrm{H} 1 \mathrm{a}$ and $\mathrm{H} 1 \mathrm{~b}$.

Two of the three proposed antecedents of probability of supply disruption drawn from transaction cost economics and resource dependence theories have significant positive relationships. As shown in Fig. 2, these antecedents explain $11.7 \%$ of the variance in the probability of supply disruption. Technological uncertainty $\left(\gamma_{31}=0.214, p<0.01\right)$ and market thinness $\left(\gamma_{32}=0.238, p<0.01\right)$ both show significant relationships providing support for $\mathrm{H} 2$ and $\mathrm{H} 4$. These findings indicate that managers purchasing direct materials in thin supply markets or markets characterized by high levels of technological uncertainty perceive a greater likelihood that a supply disruption will occur. No relationship is found between customization and the probability of supply disruption $\left(\gamma_{33}=0.085, p>0.1\right)$, failing to support H6. Based on these results, it appears that the purchase of customized products does not directly increase managers' expectations of the probability of supply disruptions.

The results of our analysis provide support for all of the hypothesized antecedents of the magnitude of supply disruptions. Technological uncertainty $\left(\gamma_{41}=0.203, p<0.01\right)$, market thinness $\left(\gamma_{42}=0.218, p<0.001\right)$, item customization $\left(\gamma_{43}=0.224, p<0.001\right)$, and item importance $\left(\gamma_{44}=0.311, p<0.001\right)$ all have positive and significant effects on managers' views of the magnitude of supply disruptions. These findings provide support for $\mathrm{H} 3, \mathrm{H} 5, \mathrm{H} 7$ and $\mathrm{H} 8$. Together these findings suggest that both market and purchased item attributes affect the perceived impact of potential supply disruptions. The antecedents in the model explain $27.4 \%$ of the variance in the magnitude of supply disruption.

Our analysis finds a positive and significant relationship $\left(\beta_{12}=0.192, p<0.01\right)$ between overall supply disruption risk and search for alternate source of supply (H9). Our results show that overall supply disruption risk accounts for $3.7 \%$ of the variance in search for alternate source of supply. While this represents a significant but relatively low percentage of the variation, we note that this decision provides a rich context that facilitates our study of the risky decision-making process. Further, we acknowledge that buyers may adopt several other supply management tactics to mitigate risks associated with supply disruption.

As shown in Fig. 2, we estimated two correlations that were exogenous to our causal model. The correlation between item customization and supply market thinness reflects the premise that customization is associated with artificially thin markets in which the buyer knowingly limits the number of suppliers that can immediately supply the customized materials (Cannon and Perreault, 1999); as expected, this correlation is positive and significant $\left(\varphi_{23}=0.192, p<0.01\right)$. Similarly, the positive and significant correlation between item importance and item customization $\left(\varphi_{34}=0.145, p<0.05\right)$ accounts for the notion that customization is associated with the perceived importance of the purchased item for the buying firm.

Finally, we controlled for size (annual sales revenue) and supplier relationship importance (minor versus major importance). The statistical significance of the paths in our model was

Table 5

Overall disruption supply risk item correlations ${ }^{\mathrm{a}}$.

\begin{tabular}{|c|c|c|c|c|c|c|c|c|c|c|c|}
\hline \multirow[t]{3}{*}{ Item } & \multirow[t]{3}{*}{ Statistic } & \multicolumn{6}{|c|}{ Perceptual measures } & \multicolumn{4}{|c|}{ Objective measures } \\
\hline & & \multicolumn{6}{|c|}{ All respondents } & \multicolumn{2}{|c|}{ All respondents } & \multicolumn{2}{|c|}{$\begin{array}{l}\text { Respondents with 5+ } \\
\text { years experience }\end{array}$} \\
\hline & & SP1 & SP2 & SP3 & SP4 & SP5 & SP6 & NSD1 & CSD1 & NSD1 & CSD1 \\
\hline OSR1 & $\begin{array}{l}\text { Corr. } \\
n\end{array}$ & $\begin{array}{l}-0.37^{* *} \\
90\end{array}$ & $\begin{array}{l}-0.18^{*} \\
90\end{array}$ & $\begin{array}{l}-0.29^{* *} \\
90\end{array}$ & $\begin{array}{l}-0.20^{*} \\
89\end{array}$ & $\begin{array}{l}-0.24^{* *} \\
89\end{array}$ & $\begin{array}{l}-0.16^{+} \\
89\end{array}$ & $\begin{array}{l}0.16^{+} \\
82\end{array}$ & $\begin{array}{l}0.18^{+} \\
63\end{array}$ & $\begin{array}{l}0.38^{*} \\
33\end{array}$ & $\begin{array}{l}0.27+ \\
26\end{array}$ \\
\hline
\end{tabular}

a Correlation $p$-values: ${ }^{+} p \leq 0.10 ;{ }^{*} p \leq 0.05 ;{ }^{* *} p \leq 0.01$. 


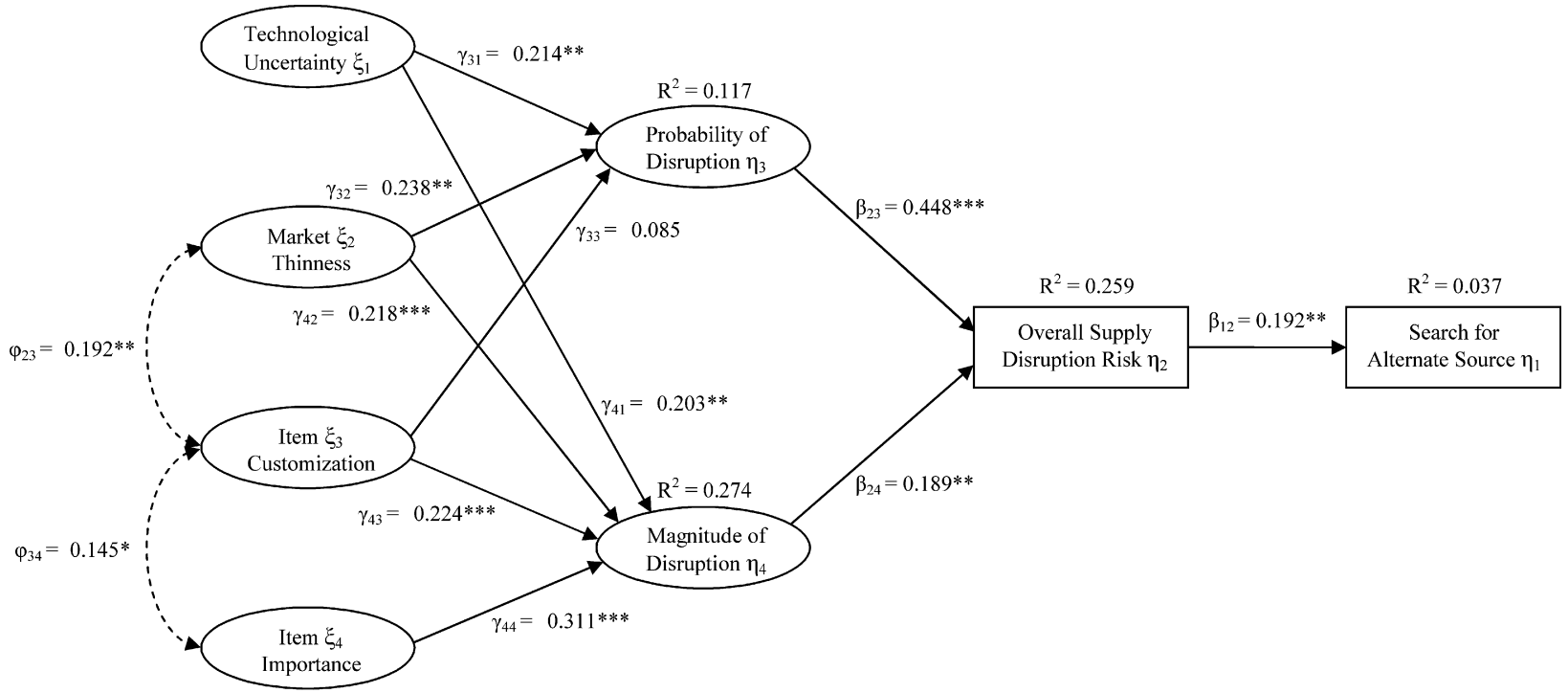

a Model fit statistics: $\chi^{2}=231.602, \mathrm{df}=160, \mathrm{p}=.000 ; \chi^{2} / \mathrm{df}=1.448 ; \mathrm{GFI}=.907 ; \mathrm{CFI}=.968 ;$ TLI $(\mathrm{NNFI})=.962 ; \mathrm{NFI}=.905 ; \mathrm{RMSEA}=.045 ; \mathrm{SRMR}=.081$
b Regression weight $\mathrm{p}$-values: $*$ denotes $\mathrm{p} \leq 0.05 ; * *$ denotes $\mathrm{p} \leq 0.01 ; * *$ denotes $\mathrm{p} \leq 0.001$

Fig. 2. Structural model-standardized regression weights $\mathrm{s}^{\mathrm{a}, \mathrm{b}}$.

${ }^{a}$ Model fit statistics: $\chi^{2}=231.602$, d.f. $=160, p=0.000 ; \chi^{2} /$ d.f. $=1.448 ;$ GFI $=0.907 ;$ CFI = 0.968; TLI $(\mathrm{NNFI})=0.962 ; \mathrm{NFI}=0.905 ; \mathrm{RMSEA}=0.045 ;$ SRMR = 0.081

${ }^{\mathrm{b}}$ Regression weight $p$-values: ${ }^{*} p \leq 0.05$; $^{* *} p \leq 0.01{ }^{* * *} p \leq 0.001$.

not affected by these additional control variables. Therefore, we conclude that our findings are robust across firm sizes and supplier relationship types.

\section{Discussion and conclusions}

Our research demonstrates the central role that representations of risk play in the risky decision-making process. Further insights into the role of risk representations may be gained by contrasting our theoretical model with alternate models in which the probability and magnitude of supply disruption constructs (Representation 1 in Fig. 1) and the overall supply disruption risk construct (Representation 2 in Fig. 1) are omitted. In our first post hoc analysis, we omit the probability and magnitude of supply disruption constructs and assess the direct effects of supply environment on overall supply disruption risk. As shown in Table 6, technological uncertainty, market thinness, item customization, and item importance directly account for just $12.2 \%$ of the variance in overall supply disruption risk, representing a 52.9\% reduction in explained variance compared to the theoretical model. As such, the inclusion of probability and magnitude of supply disruption in our model enhances our ability to

Table 6

Alternate structural models-estimation results ${ }^{\mathrm{a}}$.

\begin{tabular}{|c|c|c|}
\hline \multirow[t]{2}{*}{ Independent variables } & \multicolumn{2}{|c|}{ Dependent variables } \\
\hline & $\begin{array}{l}\text { Model } 1 \text { : } \\
\text { overall supply } \\
\text { disruption risk }\end{array}$ & $\begin{array}{l}\text { Model 2: search for } \\
\text { alternative supplier }\end{array}$ \\
\hline Technological uncertainty & $0.175^{* *}$ & \\
\hline Market thinness & $0.188^{* *}$ & \\
\hline Item customization & $0.191^{* *}$ & \\
\hline Item importance & 0.055 & \\
\hline Probability of supply disruption & & $0.113^{+}$ \\
\hline Magnitude of supply disruption & & $0.100^{+}$ \\
\hline \multicolumn{3}{|l|}{ Overall supply disruption risk } \\
\hline Coefficient of determination $\left(R^{2}\right)$ & 0.122 & 0.023 \\
\hline Percent decrease in $R^{2}$ & $52.9 \%$ & $37.8 \%$ \\
\hline
\end{tabular}

${ }^{\text {a }}$ Regression weight $p$-values: ${ }^{+} p \leq 0.10 ;{ }^{*} p \leq 0.05 ;{ }^{* *} p \leq 0.01$. explain overall supply disruption risk. We find a similar result when we omit overall supply disruption risk and analyze the direct effect of magnitude and probability of supply disruption on buyers' decisions to search for alternate sources of supply. The results in Table 6 show that probability and magnitude of disruption explain substantively less variation in search for alternate source of supply as compared to overall supply disruption $\operatorname{risk}\left(\Delta R^{2}=-37.8 \%\right)$. When generalized, the results of our post hoc analyses provide strong empirical support for the inclusion of magnitude of loss, probability of loss, and overall risk within Yates and Stone's (1992b) model of risky decision-making.

The relative effect size of the standardized regression coefficients provides new insights as to how magnitude and probability affect perceptions of overall risk. In contrast to March and Shapira (1987) and Shapira (1995), we find that probability of supply disruption $\left(\beta_{12}=0.448\right.$ ) has more than twice the effect on overall supply disruption risk than magnitude of supply disruption $\left(\beta_{13}=0.189\right)$. Whereas banking executives studied by March and Shapira (1987) tended to focus on magnitude when assessing risk, buyers and purchasing managers appear to place greater emphasis on probability when forming their perceptions of overall supply disruption risk. We offer two possible explanations for these seemingly contrary findings. First, March and Shapira (1987) suggest that executives focus on upside opportunity (magnitude) because they believe that they can effectively manage probabilities in their favor. Conversely, buyers and purchasing managers are largely focused on minimizing supply disruptions because any disruption has negative cost implications for the buying firm. Second, the contrast in views of risk may be attributable to the level of position that respondents hold. Whereas executives tend to be well compensated for taking large risks and managing these risks successfully (March and Shapira, 1987), buyers hold much less authority and are primarily responsible for ensuring the smooth flow of direct materials from the supply base (Corey, 1978).

Our empirical findings also lend new insights into the definition of overall supply disruption risk. Zsidisin (2003, p. 222) defines supply risk as "the probability of an incident associated with inbound supply from individual supply failures or the supply 
market occurring, in which its outcomes result in the inability of the purchasing firm to meet customer demand or cause threats to consumer life and safety". Importantly, several recent supply chain management studies have adopted this definition (Choi and Krause, 2006; Cooper et al., 2006; Kull and Closs, 2008; Neiger et al., in press). However, our results suggest that this definition portrays an incomplete view of supply risk. While probability of supply disruption plays a primary role in the formation of overall supply risk perceptions, we also note that magnitude of supply disruption is a significant determinant. As such, results from our study serve to caution future researchers from adopting conceptualizations of supply disruption risk that include only the probability or the magnitude of a supply disruption.

Examination of the direct and indirect effects on representations of risk provides several interesting findings. First, we note that item customization and item importance affect the magnitude of supply disruption only. This finding provides further support for the inclusion of both the probability and magnitude of supply disruption constructs in future studies of supply disruption risk. For, if magnitude was omitted from this study, we would not capture the full effects of these purchased item attributes on overall supply disruption risk. Second, product and market factors have differing effects on the probability and magnitude of supply disruption. Contrary to classical risk literature, our results support the treatment of probability and magnitude as independent constructs. Third, we find that the total indirect effect of market thinness (0.148) and technological uncertainty ( 0.134$)$ on overall supply disruption risk is much greater than that of item importance (0.059) and item customization (0.042). This finding indicates that buyers' perceptions of overall supply disruption risk increase substantially as their influence over specific attributes of the exchange decreases. For example, the level of customization is well within the control of the buying firm. However, aside from direct investment in productive resources, buyers have little immediate control over supply market thinness. Similar analogies can be drawn regarding technological uncertainty and item importance. This finding suggests that it may be particularly important for firms to invest in new supplier development and joint product development capabilities to mitigate external sources of supply disruption risk such as market thinness and technological uncertainty.

Contrary to our expectations, we find that the relationship between item customization and probability of loss is positive but not statistically significant. To explore this unexpected finding, we re-specified our theoretical model by (1) including a causal path between item customization and market thinness and (2) removing the corresponding exogenous correlation. Our exploratory findings indicate that market thinness fully mediates the relationship between item customization and probability of supply disruption. This finding suggests that transaction-specific investments which support sales of customized items impose higher switching costs to buyers, limiting the number of alternate sources of supply readily available to the buyer. As such, buyers create selfimposed thin supply markets by purchasing customized direct materials that require suppliers' specialized investment.

Results from this study inform managerial practice in several important ways. First, our process model of risky decision-making may inform organizational policy. Our research shows that direct material buyers' decisions are driven by their perception of overall supply disruption risk. Organizations may foster improved decision-making by implementing purchasing policies and procedures that facilitate buyers' translation of objective supplier performance data into accurate risk assessments. Second, our findings suggest the importance of associating attributes of exchange with specific representations of risk. Different exchange attributes may affect representations of probability and magnitude of supply disruption in different ways. Third, whereas previous conceptual research has focused on the role of disasters, terrorist attacks, and strikes, our study draws attention to the importance of considering exchange attributes as drivers of supply disruption risk. Finally, we provide validated measures to assess magnitude and probability of supply disruption; in addition to facilitating risk assessment, these measures may guide supplier segmentation (Kraljic, 1983) and portfolio approaches to supply base management (Wagner and Johnson, 2004).

While our study has important implications, it is subject to limitations. Due to the use of single respondents to capture our perceptual measures, the possibility of common method bias exists. However, our analysis suggests that the actual effect attributable to this potential bias is minimal. Second, the low response rate creates the possibility that our sample is not representative of a broader population of U.S. purchasing managers. While our tests did not indicate a significant difference between responders and nonresponders, the generalizations made from our results must be viewed in light of this potential limitation.

Despite these limitations, findings from this study may provide a useful platform for future research. To establish the generalizability of Yates and Stone's model of risky decision-making, future research may consider the role of magnitude of loss, probability of loss, and overall risk in other contexts such as new product development and strategic investment settings. Such studies may be particularly important because, unlike supply disruption risk, these contexts offer the possibility to study decisions that involve potential gains as well as losses. Additionally, risk research that examines other types of decisions may study perceptions of respondents in other professions (e.g., engineers or accountants) and levels of the organization (e.g., executives).

At a more detailed level, our behavioral model of supply disruption risk may be refined by considering additional factors that may influence perceptions of magnitude of supply disruption, probability of supply disruption, and overall supply disruption risk. Further insights may be gained by studying how referent outcomes or aspiration levels (Lopes, 1987) interact with individuals' judgments of probability and magnitude of supply disruption to affect views of overall supply disruption risk. Additional psychological factors, such as age, education, expertise, experience, cognitive ability, mood, recency of disruption, risk preference, problem framing, and prior success, may affect buyers' assessments of risk (Sitkin and Pablo, 1992). Study of these behavioral factors may facilitate improved design of organizational structure and infrastructure that supports the risky decision-making process.

The supply chain management literature identifies several factors that may also impact perceptions of supply disruption risk. While the influence of product and supplier factors were empirically examined within the context of our study, several others warrant attention in future research. For example, Sheffi and Rice (2005) consider several external hazards such as strikes (e.g., US West Coast longshoremen strike), natural disasters, outbreak of disease, and terrorist attacks in their discussion of risk assessment and mitigation. Other research highlights the role of density of the supply network (Craighead et al., 2007), complexity of the supply network (Choi and Krause, 2006), supplier performance (Spekman and Davis, 2004), supplier shutdowns due to strikes, fires, financial distress, or sabotage (Sheffi and Rice, 2005), and shipping distance. Further, factors related to supply network complexity, such as geopolitical, natural, or socio-cultural factors may also contribute to supply disruption risk (e.g., Juttner, 2005). The simultaneous consideration of these drivers of supply disruption risk and their interactions (e.g., the interaction of natural disasters and density of supply network) may lend new insight into how particular disruption events affect perceptions.

Another rich avenue for future scientific investigation involves the examination of risk mitigation strategies. While our model of 
overall supply disruption risk does not focus on risk mitigation strategies, it does advance a context in which the conditional effectiveness of risk reducing activities may be studied. Previous research suggests that the number of suppliers for a particular purchased product, the size and location of inventory within the supply chain (Kull and Closs, 2008), use of early supplier involvement practices (Petersen et al., 2005), the adoption of specific supplier selection criteria (Talluri et al., 2006), the development of existing or new suppliers (Krause, 1999), and integration of logistical transportation and information systems (Kaynak and Hartley, 2006) may attenuate supply disruption risk. Additional risk mitigation tactics include: (1) contingency planning (Sheffi and Rice, 2005), (2) suppliers' investments in flexible manufacturing, back-up systems, and spare capacity, (3) buyer's investments in in-house manufacturing capabilities, and (4) buyer's and supplier's joint investment in the development of relational norms. Future research should operationalize these mitigation strategies and examine their influence on buyers' perceptions of magnitude of supply disruption, probability of supply disruption, and overall supply disruption risk with respect to the relationships shown in our model.

\section{References}

Anderson, E., Weitz, B., 1989. Determinants of continuity in conventional industria channel dyads. Marketing Science 8 (4), 310-323.

Armstrong, J.S., Overton, T.S., 1977. Estimating nonresponse bias in mail surveys. Journal of Marketing Research 14 (3), 396-402.

Auster, E.R., 1992. The relationship of industry evolution to patterns of technological linkages, joint ventures, and direct investment between U.S. and Japanese firms. Management Science 17 (3), 1-25.

Baird, I.S., Thomas, H., 1985. Toward a contingency model of strategic risk taking. Academy of Management Review 10 (2), 230-243.

Bensaou, M., Anderson, E., 1999. Buyer-supplier relations in industrial markets: when do buyers risk making idiosyncratic investments. Organizational Science 10 (4), 460-481.

Bollen, K.A., 1989. Structural Equations with Latent Variables. Wiley, New York.

Byrne, B.M., 2006. Structural Equation Modeling with EQS, 2nd ed. Lawrence Erlbaum Associates, Mahwah, NJ

Cannon, J.P., Perreault, W.D., 1999. Buyer-seller relationships in business markets Journal of Marketing Research 36 (4), 439-460.

Choi, T.Y., Krause, D.R., 2006. The supply base and its complexity: implications for transaction cost, risks, responsiveness, and innovation. Journal of Operations Management 24 (5), 637-652.

Churchill Jr., G.A., 1979. Measure and construct validity studies. Journal of Marketing Research 16 (1), 64-73.

Clark, K.B., Fujimoto, T., 1990. The power of product integrity. Harvard Business Review (November-December), 107-118.

Cooper, M.J., Wakefield, K.L., Tanner, J.F., 2006. Industrial buyers' risk aversion and channel selection. Journal of Business Research 59 (6), 653-661.

Corey, E.R., 1978. Procurement management, strategy, organization and decisionmaking. CBI Publishing Company, Boston.

Cox, D.F., Rich, S.U., 1964. Perceived risk and consumer decision-making-the case of telephone shopping. Journal of Marketing Research 1 (4), 32-39.

Craighead, C.W., Blackhurst, J., Rungtusanatham, M.J., Handfield, R.B., 2007. The severity of supply chain disruptions: design characteristics and mitigation capabilities. Decision Sciences 38 (1), 131-156.

Cunningham, S.M., 1967. The Major Determinants of Perceived Risk. Harvard University, Boston

Dash, J.F., Schiffman, L.G., Berenson, C., 1976. Risk- and personality-related dimensions of store choice. Journal of Marketing 40 (1), 32-39.

Dowling, G.R., Staelin, R., 1994. A model of perceived risk and intended riskhandling activity. Journal of Consumer Research 21 (1), 119-134.

Dyer, J.H., Singh, H., 1998. The relational view: cooperative strategy and sources of interorganizational competitive advantage. Academy of Management Review 23 (4), 660-679.

Fischhoff, B., 1992. Risk taking: a developmental perspective. In: Yates, J.F. (Ed.), Risktaking Behaviour. John Wiley \& Sons, New York, pp. 133-162.

Fornell, C., Larcker, D.F., 1981. Evaluating structural equation models with unobservable variables and measurement error. Journal of Marketing Research 18 (1), 39-50.

Gassenheimer, J.B. Monolis, C., 2001. The influence of product customization and supplier selection on future intentions: the mediating effects of salesperson and organizational trust. Journal of Managerial Issues 13 (4), 418-435.

Grover, V., Malhotra, M.K., 2003. Transaction cost framework in operations and supply chain management research: theory and measurement. Journal of Operations Management 21 (4), 457-473.

Hahn, C.K., Kim, K.H., Kim, J.S., 1986. Costs of competition: implications for purchasing strategy. Journal of Purchasing and Materials Management 22 (3), 2-7.
Hallen, L., Johanson, J., Seyed-Mohamed, N., 1991. Inter-firm adaptation in business relationships. Journal of Marketing 55 (2), 29-37.

Hegde, V.G., Kekre, S., Rajiv, S., Tadikamalla, P.R., 2005. Customization: impact on product and process performance. Production and Operations Management 14 (4), 388-399.

Hendricks, K.B., Singhal, V.R., 2003. The effect of supply chain glitches on shareholder wealth. Journal of Operations Management 21 (5), 501-522.

Hendricks, K.B., Singhal, V.R., 2005a. Supply chain glitches and operating performance. Management Science 51 (5), 695-711.

Hendricks, K.B., Singhal, V.R., 2005b. An empirical analysis of the effect of supply chain disruptions on long-run stock price performance and equity risk of the firm. Production and Operations Management 14 (1), 35-52.

Hu, L.T., Bentler, P.M., 1998. Fit indices in covariance structure modeling: sensitivity to underparameterized model misspecification. Psychological Methods 3 (4), 424-453.

Hu, L.T., Bentler, P.M., 1999. Cutoff criteria for fit indexes in covariance structure analysis: conventional criteria versus new alternatives. Structural Equation Modeling 6 (1), 1-55.

Johnston, W.J., Lewin, J.E., 1996. Organizational buying behavior: toward an integrative framework. Journal of Business Research 35, 1-15

Juttner, U., 2005. Supply chain risk management: understanding the business requirements from a practitioner perspective. The International Journal of Logistics Management 16 (1), 120-141.

Kahneman, D., Tversky, A., 1979. Prospect theory: an analysis of decision under risk. Econometrica 47 (2), 263-291.

Kaplan, S., Garrick, B.J., 1981. On the quantitative definition of risk. Risk Analysis 1 (1), 11-27.

Kaplan, L.B., Szybillo, G.J., Jacoby, J., 1974. Components of perceived risk in product purchase. Journal of Applied Psychology 59 (3), 287-291.

Kaynak, H., Hartley, J.L., 2006. Using replication research for just-in-time purchasing construct development. Journal of Operations Management 24 (6), 868-892.

Kim, S.K., Yamada, T., Kim, H., 2008. Search for alternatives and collaboration with incumbents: two-sided sourcing behavior in business markets. Decision Sciences 39 (1), 85-114

Kleindorfer, P., Saad, G., 2005. Managing disruption risks in supply chains. Production and Operations Management 14 (1), 53-68.

Kogan, N., Wallach, M.A., 1964. Risk Taking: A Study in Cognition and Personality. Holt, Rinehart and Winston, New York.

Kraljic, P., 1983. Purchasing must become supply management. Harvard Business Review (September-October), 109-117.

Krause, D.R., 1999. The antecedents of buying firms' efforts to improve suppliers. Journal of Operations Management 17 (2), 205-224.

Kull, T., Closs, D., 2008. The risk of second-tier supplier failures in serial supply chains: implications for order policies and distributor autonomy. European Journal of Operational Research 186 (3), 1158-1174.

Lazzarini, S.G., Claro, D.P., Mesquita, L.F., 2008. Buyer-supplier and supplier-supplier alliances: do they reinforce or undermine one another? Journal of Management Studies 45 (3), 561-584.

Lopes, L.L., 1987. Between hope and fear: the psychology of risk. In: Berkowitz, L. (Ed.), Advances in Experimental Social Psychology, vol. 20. Academic Press, New York, pp. 255-295.

Mao, J.C.T., 1970. Survey of capital budgeting: theory and practice. Journal of Finance 25 (2), 349-360.

McNamara, G., Bromiley, P., 1999. Risk and return in organizational decision making. Academy of Management Journal 42 (3), 330-339.

March, J.G., Shapira, Z., 1987. Managerial perspectives on risk and risk taking. Management Science 33 (11), 1404-1418.

Mintzberg, H., 1978. Patterns in strategy formation. Management Science 24 (9), 934-948.

Mitchell, V.-W., 1999. Consumer risk perception: conceptualizations and models. European Journal of Marketing 33 (1/2), 163-195.

Neiger, D., Rotaru, K., Churilov, L., in press. Supply chain risk identification with value-focused process engineering. Journal of Operations Management, 1-15.

Perdue, B.C., Summers, J.O., 1991. Purchasing agents' use of negotiation strategies. Journal of Marketing Research 28 (2), 175-189.

Peter, J.P., Ryan, M.J., 1976. An investigation of perceived risk at the brand level. Journal of Marketing Research 13 (2), 184-188.

Petersen, K.J., Handfield, R.B., Ragatz, G.L., 2003. A model of supplier integration into new product development. Journal of Product Innovation Management 20, 284-299.

Petersen, K.J., Handfield, R.B., Ragatz, G.L., 2005. Supplier integration into new product development: coordinating product, process and supply chain design. Journal of Operations Management 23 (3-4), 371-388.

Pfeffer, J., Salancik, G.R., 1978. The External Control of Organizations. Harper and Row, New York

Podsakoff, P.M., Organ, D.W., 1986. Self-reports in organizational research: problems and prospects. Journal of Management 12 (4), 531-544.

Qualls, W.J., Puto, C.P., 1989. Organizational climate and decision framing: an integrated approach to analyzing industrial buying decisions. Journal of Marketing Research 26 (May), 179-192.

Scott Jr., D.F., Petty, J.W., 1984. Capital budgeting practices in large American firms: a retrospective analysis and synthesis. Financial Review 19 (1), 111-123.

Shapira, Z., 1995. Risk Taking: A Managerial Perspective. Russel Sage Foundation, New York.

Sheffi, Y., Rice Jr., J., 2005. A supply chain view of the resilient enterprise. MIT Sloan Management Review 47 (1), 41-48. 
Sitkin, S.B., Pablo, A.L., 1992. Reconceptualizing the determinants of risk behavior. The Academy of Management Review 17 (1), 9-38.

Slovic, P., 1987. Perception of risk. Science 236, 280-285.

Smeltzer, L.R., Siferd, S.P., 1998. Proactive supply chain management: the management of risk. International Journal of Purchasing and Materials Management (Winter), 38-45.

Spekman, R.E., Davis, E.W., 2004. Risky business: expanding the discussion on risk and the extended enterprise. International Journal of Physical Distribution and Logistics Management 34 (5), 414-433.

Stuart, I., Decker, P., McCutcheon, D., Kunst, R., 1998. A leveraged learning network. Sloan Management Review 39 (4), 81-92.

Stump, R.L., Athaide, G.A., Joshi, A.W., 2002. Managing seller-buyer new product development relationships for customized products: a contingency model based on transaction cost analysis and empirical test. Journal of Product Innovation Management 19 (6), 439-454.

Stump, R.L., Heide, J.B., 1996. Controlling supplier opportunism in industrial relationships. Journal of Marketing Research 33 (4), 431-441.

Sullivan, K., Kida, T., 1995. The effect of multiple reference points and prior gains and losses on managers' risky decision making. Organizational Behavior and Human Decision Processes 64 (1), 76-83.

Talluri, S., Narasimhan, R., Nair, A., 2006. Vendor performance with supply risk: a chance-constrained DEA approach. International Journal of Production Economics 100 (2), 212-222.

Treleven, M., Schweikhart, S.B., 1988. A risk/benefit analysis of sourcing strategies: single vs. multiple sourcing. Journal of Operations Management 7 (4), 93-114.
Ulrich, D., Barney, J.B., 1984. Perspectives in organizations: resource dependence, efficiency, and population. Academy of Management Review 9 (3), 471-481.

Ulrich, K.T., Ellison, D.J., 1999. Holistic customer requirement and the design-select decision. Management Science 45 (5), 641-658.

Wagner, S.M., Johnson, J.L., 2004. Configuring and managing strategic supplier portfolios. Industrial Marketing Management 33, 717-730.

Williamson, O.E., 1985. The Economic Institutions of Capitalism. Free Press, New York.

Williamson, O.E., 1991. Comparative economic organization: the analysis of discrete structural alternatives. Administrative Science Quarterly 36 (2), 269-296.

Yates, J.F., 1990. Judgment and Decision Making. Englewood Cliffs, Prentice Hall.

Yates, J.F., Stone, E.R., 1992a. The risk construct. In: Yates, J.F. (Ed.), Risk-taking Behavior. John Wiley \& Sons, New York, pp. 1-25.

Yates, J.F., Stone, E.R., 1992b. Risk appraisal. In: Yates, J.F. (Ed.), Risk-taking Behavior John Wiley \& Sons, New York, pp. 49-85.

Yates, J.F., Stone, E.R., Parker, A.M., 1994. Risk communication: absolute versus relative expressions of low-probability risks. Organizational Behavior and Human Decision Processes 60, 387-408.

Yeh, Y., 2005. Identification of factors affecting continuity of cooperative electronic supply chain relationships: empirical case of the Taiwanese motor industry. Supply Chain Management: An International Journal 10 (4), 327-335.

Zsidisin, G.A., 2003. A grounded definition of supply risk. Journal of Purchasing and Supply Management 9, 217-224.

Zsidisin, G.A., Smith, M.F., 2005. Managing supply risk with early supplier involvement: a case study and research propositions. Journal of Supply Chain Management 41 (4), 44-57. 